deficiency were treated with growth hormone, at a lower individual dosage, and for a shorter time. With the more widespread use of growth hormone, and particularly with its current use in immunosuppressed patients, review of its safety is essential. Children treated with cranial irradiation account for the largest group of children with growth hormone deficiency due to an organic lesion, and growth hormone has proved benefits in this group. It is encouraging that there is no increased risk of tumour recurrence in our children in whom growth hormone therapy has been used. Caution must still exist, however, and continuing surveillance is crucial.

We thank Serono Laboratories (UK) for financial support and the Manchester Children's tumour registry, which is supported by the Cancer Research Campaign .

1 Clayton PE, Shalet SM, Gattamaneni HR, Price DA. Does growth hormone cause relapse of brain tumours? Lancet 1987;i:711-3.

2 Arslanian SA, Becker DJ, Lee PA, Drash LA, Foley TP. Growth hormone and tumor recurrence. Findings in children with brain neoplasms and hypopituitarism. Am f Dis Child 1985;139:347-50.

3 Rodens KP, Kaplan SL, Grumbach MM, Teller WM. Does growth hormone therapy increase the frequency of tumor recurrence in children with brain tumors? Acta Endocrinol (Copenh) 1987;283 (suppl): 188-9.

4 Buchanan CR, Preece MA, Milner RDG. Mortality, neoplasia, and Creutzfeldt-Jakob disease in patients treated with human pituitary growth hormone in the United Kingdom. BMF 1991;302:824-8.

5 Cox DR. Regression models and life-tables (with discussion). Fournal of the Royal Statistical Society 1972;34[B]:187-220.

6 Cox DR, Oakes D. Analysis of survival data. London: Chapman and Hall, 1984:112-41

7 Clayton PE, Shalet SM. Dose dependency of onset of radiation-induced growth hormone deficiency. F Pediatr 1991;118:226-8.

8 Bentley HB, Hughes ER, Peterson RDA. Effect of hypophysectomy on a virus-induced T-cell leukaemia. Nature 1974;252:747-8.

9 Rogers PC, Komp D, Rogol A, Sabio H. Possible effect of growth hormone on development of acute lymphoblastic leukaemia. Lancet 1977;ii:434-5.

10 Estrov Z, Meir R, Barak Y, Zaizov R, Zadik Z. Human growth hormone and insulin-like growth factor- 1 enhance the proliferation of human leukemic cells. I Clin Oncol 1991:9:394-9.

11 Moon HD, Simpson ME, Li CH, Evans HM. Neoplasms in rats treated with pituitary growth hormone. I. Pulmonary and lymphatic tissues. Cancer Res 1950;10:297-308.

12 Ezzat S, Melmed S. Are patients with acromegaly at increased risk for neoplasia? I Clin Endocrinol Metab 1991;72:245-9.

13 Watanabe S, Tsunematsu Y, Fujimoto J, Komiyama A. Leukaemia in patients treated with growth hormone. Lancet 1988; i: 1159.

14 Delemarre-Van de Waal HA, Ondink JH, de Grauw TJ, de Waal FC. Leukaemia in patients treated with growth hormone. Lancel 1988;i:1159.

15 Fisher DA, Job J-C, Preece MA, Underwood LE. Leukaemia in patient treated with growth hormone. Lancet 1988;i:1159-60.

(Accepted 27 April 1992)

\title{
Effect of serotesting with counselling on condom use and seroconversion among HIV discordant couples in Africa
}

\author{
Susan Allen, Jeffrey Tice, Philippe Van de Perre, Antoine Serufilira, Esther Hudes, \\ Francois Nsengumuremyi, Joseph Bogaerts, Christina Lindan, Stephen Hulley
}

\section{Department of Pathology, University of California, San Francisco}

Susan Allen

\section{Division of Clinica}

Epidemiology, Department of Epidemiology and Biostatistics, and Center for AIDS Prevention Studies, University of California, San Francisco Jeffrey Tice

Esther Hudes

Christina Lindan

Stephen Hulley

Projet San Francisco, Kigali, and Ministry of Health, Rwanda

Antoine Serufilira

Francois Nsengumuremyi

\section{National AIDS Control}

Program, Kigali, Rwanda

Philippe Van de Perre

\section{Centre Hospitalier de \\ Kigali}

Joseph Bogaerts

Correspondence and requests for reprints to:

Dr Susan Allen, 74 New

Montgomery St, Suite 600,

San Francisco, CA 94105 ,

USA.

BM于 1992;304: 1605-9

\section{Abstract}

Objective-To determine whether HIV testing and counselling increased condom use and decreased heterosexual transmission of HIV in discordant couples.

Design-Prospective study.

Setting-Kigali, the capital of Rwanda.

Subjects-Cohabiting couples with discordant HIV serology results.

Main outcome measures-Condom use in the couple and HIV seroconversion in the negative partners.

Results - 60 HIV discordant couples were identified, of whom 53 were followed for an average of $2 \cdot 2$ years. The proportion of discordant couples using condoms increased from $4 \%$ to $57 \%$ after one year of follow up. During follow up two of the 23 HIV negative men and six of the $\mathbf{3 0}$ HIV negative women seroconverted (seroconversion rates of 4 and 9 per 100 person years). The rate among women was less than half that estimated for similar women in discordant couples whose partners had not been serotested. Condom use was less common among those who seroconverted $(100 \% v 5 \%, p=0.01$ in men; $67 \% v 25 \%, p=0 \cdot 14$ in women).

Conclusions-Roughly one in seven cohabiting couples in Kigali have discordant HIV serological results. Confidential HIV serotesting with counselling caused a large increase in condom use and was associated with a lower rate of new HIV infections. HIV testing is a promising intervention for preventing the spread of HIV in African cities.

\section{Introduction}

The major route of HIV transmission in Africa is heterosexual intercourse. ${ }^{1-3}$ Genital ulcerations, use of hormonal contraceptives, lack of male circumcision, and the clinical status of the index case have been implicated as risk factors in transmission of HIV. ${ }^{2+8}$ As with gonorrhoea, gender is also thought to have a role, with male to female transmission being more efficient than female to male transmission. ${ }^{9}$ However, the importance of these factors in explaining the high prevalence of infection in Africa and their utility in designing effective prevention programmes are unknown.

Cohort studies of HIV discordant couples (one partner HIV positive, the other HIV negative) that monitor the risk factors, sexual behaviour, and HIV status of both partners over time provide data for examining the determinants of heterosexual transmission. Studies of discordant couples in the United States have found a wide variation in reported rates of infection among the heterosexual partners of people infected with $\mathrm{HIV}^{6}{ }^{10}$; the lack of a detectable association between the number of acts of sexual intercourse and the risk of infection ${ }^{911-13}$ suggests the presence of other factors affecting HIV infectivity and susceptibility.

The aim of this study is to evaluate the effectiveness of a prevention programme linking confidential HIV serotesting with a programme for counselling and providing condoms to urban couples. We report here the factors associated with risk reduction (particularly, the use of latex condoms) and seroconversion among 53 HIV discordant couples followed prospectively for two years in the capital of Rwanda in Africa.

\section{Subjects and methods}

SUBJECTS

In 1986 the Projet San Francisco was established in Kigali, Rwanda, by the University of California in San Francisco in collaboration with the National AIDS Program of Rwanda. During 1986 and 1987 a consecutive, population based sample of 3702 women aged 18-35 was screened for HIV at the prenatal and paediatric outpatient clinics of the Centre Hospitalier de Kigali. ${ }^{14}$ Stratified random samples of 460 HIV positive and 998 HIV negative women were recruited in $1988^{15}$ for longitudinal studies of the predictors of 
behaviour change and seroconversion in the HIV negative cohort and of progression to HIV disease in the HIV positive cohort.

The study provided free HIV testing and counselling to women study subjects (routinely as part of enrolment procedures) and their male sexual partners (on a volunteer basis). Of the 1458 women, 1258 were in cohabiting unions; $420(33 \%)$ of their husbands requested testing. Fifty seven couples discordant for HIV were identified and all were invited to enrol in this prospective study; 51 couples agreed to participate. Two of three additional discordant couples were enrolled when women in concordant negative couples seroconverted during follow up of the larger cohort study, bringing the total number of enrolled discordant couples to 53 .

\section{INTERVENTION}

After providing informed consent, each couple saw an educational video about AIDS presented in the national language (Kinyarwanda) and participated in a discussion group led by a Rwandan social worker. In addition to general information about AIDS and HIV prevention, the educational video discussed the role of condoms and spermicide containing nonoxynol 9 in AIDS prevention and explained the limitations of our knowledge about their efficacy. Condoms, presented as the most effective AIDS prevention method, and spermicidal suppositories were offered free of charge to all study subjects. A project counsellor distributed HIV test results individually, in sealed envelopes, to preserve confidentiality. The project suggested that couples receive their results together and discuss the implications of their HIV status with the counsellor.

\section{DATA COLLECTION}

Before the intervention Rwandan social workers administered a questionnaire concerning demographic characteristics, risk factors for HIV infection, sexual history, and signs and symptoms associated with HIV. Rwandan nurses performed a physical examination and took specimens for laboratory tests including HIV serology, packed cell volume, total white blood cell count with differential, sedimentation rate, gonorrhoea culture, rapid plasma reagent for syhilis, and two stool examinations. Serum samples from both partners were frozen for later studies.

\section{FOLLOW UP}

Seronegative partners were asked to return for repeat blood sampling at two week intervals for three months to rule out immediate seroconversion. Both partners subsequently returned to the clinic at three month intervals. During these visits a questionnaire pertaining to sexual activity (number of episodes of intercourse with and without correct use of condoms or spermicides) was administered. Data were verified using sexual activity calendars filled out by each couple. Blood was also drawn for repeat blood tests. The medical history was repeated every six months and the physical examination was repeated yearly. Health care for both partners was provided free of charge at a clinic run by the project so that changes in health status could be monitored more closely. Data from the medical records of these visits were included in the semiannual medical history. A health team was sent to the homes of couples who missed scheduled visits to encourage continued participation by the couple and to update follow up information.

\section{SEROLOGICAL TESTING}

Sera were initially tested for HIV-1 by a commercial enzyme linked immunosorbent assay (ELISA) (Wellcome Diagnostics, Dartford, England) at the Rwandan National AIDS Control Program laboratory in Kigali.
Positive ELISA tests were confirmed by commercial western blot (DuPont, Wilmington, Delaware). The laboratory also confirmed with western blotting the results initially obtained from negative partners in discordant pairs. In cases of seroconversion, the laboratory tested previous samples with western blotting (a more sensitive test in the early stages of infection) to pinpoint accurately the time of infection. The presence of at least one band reactive to a core protein and one band reactive to an envelope protein of HIV-1 defined a positive response. Samples reactive to a single core protein were considered to be indeterminate and counted as negative for the purposes of analysis.

\section{DATA ANALYSIS}

Analyses for this paper were limited to the 1258 women who reported having a cohabiting sexual partner. To assess the generalisability of our findings, the demographic characteristics and sexual histories of the 420 women whose partners volunteered for HIV testing were compared with those of the women whose partners were not tested. The proportion of discordant couples who used condoms after HIV testing and counselling was compared with that in women whose partners' HIV status was unknown. Among couples with HIV positive men, those in which the woman seroconverted were compared with non-seroconverting couples with respect to condom use, literacy, marital status, and whether the male partner had other partners or used alcohol. Comments regarding male seroconverters are descriptive as their small number prohibited comparative analyses of variables.

Descriptive data are presented as means, raw percentages, or rates. Bivariate associations were analysed with the $\chi^{2}$ test for categorical variables. Fisher's exact test was used for two dichotomous variables with small numbers. Comparison of means was performed using the two sample $t$ test (for normally distributed variables) or the Wilcoxon rank sum test (for non-normally distributed variables) by means of the SAS statistical package. Statistical significance in differences over time between seroconversion in men and women were evaluated using a KaplanMeier survival analysis with a Wilcoxon test for censored observations. A two sided $\alpha$ level of 0.05 was used as the criterion of statistical significance throughout. Confidence intervals for rates were computed using the square root transformation for Poisson counts. ${ }^{16}$ When the observed count was 0 a one sided $95 \%$ confidence interval was computed based on the exact relation between the Poisson and $\chi^{2}$ distributions. ${ }^{17}$

\section{Results}

\section{CHARACTERISTICS OF SUBJECTS}

Table I compares the general characteristics of the 420 women whose regular sexual partners came in for HIV testing with those of the remaining 838 women who also reported a cohabiting partner. The subjects were young women with few lifetime sexual partners supporting a median of three living children. There were no significant differences in HIV status, religion, marital status, or measures of sexual activity such as mean number of lifetime sexual partners and history of sexually transmitted diseases between the two groups. However, only $75 \%$ of the women whose partners were tested were literate while $86 \%(p<0.001)$ of the remaining women were literate. The partners who did not come in for testing were also more likely to speak French $(60 \% v 48 \%, \mathrm{p}<0.001)$.

Fourteen per cent $(57 / 420)$ of the couples with HIV test results for both partners were discordant for HIV; the woman was positive for HIV in 25 couples and the 
man in 32. Twenty five per cent $(103 / 420)$ of the couples were concordant positive and $62 \%(260 / 420)$ were concordant negative. Eighty per cent (103/128) of the male partners of HIV positive women were positive for HIV while only $11 \%(32 / 292)$ of the partners of HIV negative women were HIV positive $(p<0.001)$. Similarly, $76 \%$ (103/135) of the female partners of HIV positive men were positive for HIV while $9 \%(25 / 285)$ of the partners of HIV negative men were HIV positive.

Fifteen of the $25 \mathrm{HIV}$ positive women in discordant couples $(60 \%)$ reported only one lifetime sexual partner. Only two of these women reported ever having received a blood transfusion and neither of these women's transfusions occurred before 1986, when HIV screening of the blood supply was implemented in Rwanda.

Fifty one of the 57 discordant couples were enrolled in the study for follow up; those not enrolled included two couples who separated on hearing their HIV test results, three couples who declined to participate, and one in which the HIV positive partner died before the couple could be enrolled. Nine of the remaining couples dropped out of the study during follow up (four separated, in three one partner died, two are still together). Three women who were initially in concordant negative couples seroconverted during the first

TABLE I-Baseline characteristics of women living with a steady sexual partner. Values are numbers (percentages) unless otherwise indicated

\begin{tabular}{|c|c|c|c|}
\hline & $\begin{array}{l}\text { Partner tested } \\
\text { for HIV } \\
(n=420)\end{array}$ & $\begin{array}{l}\text { Partner not tested } \\
\text { for HIV } \\
(n=838)\end{array}$ & $\mathrm{p}$ Value \\
\hline HIV antibody positive & $127(30)$ & $230(27)$ & $0 \cdot 30$ \\
\hline \multicolumn{4}{|l|}{ Mean (SD) age (years): } \\
\hline Woman & $29(4)$ & $29(4)$ & 0.75 \\
\hline Man & $35(7)$ & $36(7)$ & 0.46 \\
\hline \multicolumn{4}{|l|}{ Literate (Kinyarwanda): } \\
\hline Woman & $317(75)$ & $721(86)$ & $<0 \cdot 01$ \\
\hline Man & $381(91)$ & $763(91)$ & $0 \cdot 84$ \\
\hline Religion: & & & 0.75 \\
\hline Catholic & $301(72)$ & $586(70)$ & \\
\hline Other Christian & $78(18)$ & $153(18)$ & \\
\hline Muslim & $38(9)$ & $92(11)$ & \\
\hline None & $3(1)$ & $7(1)$ & \\
\hline Legally married & $223(53)$ & $418(50)$ & $0 \cdot 28$ \\
\hline Faithful couple & $172(41)$ & $319(38)$ & $0 \cdot 32$ \\
\hline Mean (SD) length of union (years) & $8(4)$ & $8(4)$ & 0.94 \\
\hline \multicolumn{4}{|l|}{ Woman's sexual partners: } \\
\hline More than one in life & $100(24)$ & $218(26)$ & $0 \cdot 40$ \\
\hline More than one in past year & $3(1)$ & $13(2)$ & $0 \cdot 21$ \\
\hline Man sees prostitutes & $79(19)$ & $153(18)$ & 0.81 \\
\hline \multicolumn{4}{|l|}{ History of sexually transmitted disease: } \\
\hline Woman (past 1 year) & $25(6)$ & $50(6)$ & 0.99 \\
\hline Man (past 2 years) & $82(20)$ & $140(17)$ & $0 \cdot 22$ \\
\hline
\end{tabular}

*The woman reported that neither partner had other sexual partners.

TABLE II-Seroconversion rates in discordant couples

\begin{tabular}{lccc}
\hline & $\begin{array}{c}\text { Woman negative, } \\
\text { man positive } \\
(\mathbf{n}=30)\end{array}$ & $\begin{array}{c}\text { Woman positive, } \\
\text { man negative } \\
(\mathbf{n}=23)\end{array}$ & p Value \\
\hline Mean (SD) length of follow up (days) & $769(338)$ & $841(304)$ & \\
$\begin{array}{l}\text { No of seroconverters } \\
\text { Seroconversion rate per 100 person years }\end{array}$ & 6.5 & 2 & $0.31^{\star}$ \\
$\begin{array}{l}\text { Seroconversion rate per 100 person years, } \\
\text { excluding two women who were probably } \\
\text { already infected at baseline }\end{array}$ & 6.4 & 3.8 & \\
\hline
\end{tabular}

^Calculated with survival analysis; Kaplan-Meier analysis, Wilcoxon's test for censored observations.

TABLE III-Condom use among discordant couples after HIV testing and counselling. Values are numbers (percentages) of couples

\begin{tabular}{|c|c|c|c|c|c|c|}
\hline & \multicolumn{3}{|c|}{ Woman HIV negative } & \multicolumn{3}{|c|}{ Man HIV negative } \\
\hline & $\begin{array}{c}\text { Non- } \\
\text { converters } \\
(n=24)\end{array}$ & $\begin{array}{c}\text { Converters } \\
(\mathrm{n}=6)\end{array}$ & p Value ${ }^{\star}$ & $\begin{array}{c}\text { Non- } \\
\text { converters } \\
(\mathbf{n}=21)\end{array}$ & $\begin{array}{c}\text { Converters } \\
(\mathbf{n}=2)\end{array}$ & p Value \\
\hline Using condomst & $18(75)$ & $2(33)$ & $0 \cdot 14$ & $20(95)$ & 0 & 0.01 \\
\hline Every time & $4(17)$ & 0 & 0.56 & $5(24)$ & 0 & 1.00 \\
\hline Sometimes & $14(58)$ & $2(33)$ & $0 \cdot 38$ & $15(71)$ & 0 & $0 \cdot 11$ \\
\hline Never using condoms & $6(25)$ & $4(67)$ & $0 \cdot 14$ & $1(5)$ & $2(100)$ & 0.01 \\
\hline
\end{tabular}

*Calculated using two tailed Fisher's exact test.

†Alone or in conjunction with spermicidal suppositories. year of follow up; two of the couples were enrolled in the prospective study and the third couple separated.

\section{RISK REDUCTION BEHAVIOURS}

Although only two (3\%) of the women and four (7\%) of the men in the 60 discordant couples had used condoms before the beginning of the study, at the one year follow up $57 \%$ (34) of the discordant couples were using condoms compared with $16 \%(131 / 838, \mathrm{p}<0 \cdot 001)$ of the remainder of the larger cohort of cohabiting couples. The proportion of discordant couples using spermicides $(12 \%)$ was similar in the rest of the cohort $(10 \%, \mathrm{p}=0 \cdot 68)$.

Among discordant couples in which the man was HIV positive, the median number of unprotected episodes of sex per month was one (range 0-23) compared with a median of zero (0-14) episodes per month among couples with an HIV positive woman $(\mathrm{p}=0.05$, Wilcoxon's rank sum test). In particular, $87 \%$ of discordant couples with an HIV negative man used condoms at some time during the follow up period compared with $70 \%$ condom use in discordant couples with an HIV negative woman $(p=0 \cdot 12)$. All but nine couples reported at least one episode of unprotected intercourse during the follow up period.

\section{SEROCONVERSION RATES IN MEN}

Two men in discordant couples seroconverted during the follow up period for an observed rate of $3 \cdot 8 / 100$ person years (table II). One man seroconverted during the first three months of follow up, though western blotting at baseline did not show any bands suggestive of early seroconversion. The other man seroconverted within the first year of follow up. Both male seroconverters said they never used condoms but only one of the 21 non-converting men reported never using condoms $(p=0 \cdot 01$, table III). The mean frequency of unprotected sexual intercourse did not differ significantly between seroconverters and nonconverters. The range of total number of unprotected exposures for HIV negative men was $0-132$; of the seroconverters, one reported four unprotected exposures and the other reported 40 . The 23 couples reported a total of 572 episodes of unprotected intercourse during follow up. Thus, the number of transmissions for each reported unprotected contact was 286.

Both of the men who seroconverted had occasionally had other sexual partners. Both couples in which the man seroconverted had lived together for only three years (the other couples had been together a mean of seven years $(p<0 \cdot 001)$. Both couples had had sexual intercourse when the man had been drinking.

\section{SEROCONVERSION RATES IN WOMEN}

Six women seroconverted during the follow up period, an observed seroconversion rate of $9 \cdot 5 / 100$ person years (table II). Two of the women seroconverted within seven weeks of enrolment of their sexual partner, and their western blots at baseline showed prominent bands at p24. Although an isolated indeterminate result of this type is not diagnostic of early infection, it is likely in light of seroconversion several weeks later that these two subjects had been infected with HIV at enrolment. ${ }^{18}$ If they are excluded from the analysis the seroconversion rate is $6 \cdot 4 / 100$ person years.

Seroconverters were less likely to be condom users, and none reported having used condoms every time (table III). The range of the total number of unprotected episodes of sex for HIV negative women was $0-700$, and for seroconverting women it was $4-60$. The 30 couples reported a total of 2099 episodes of unprotected intercourse during the follow up period 
Thus the number of transmissions for each unprotected contact was 350 .

Table IV compares seroconversion rates in HIV negative women in selected strata. In contrast to the high literacy rates in the overall sample (table I), all six seroconverters were illiterate or had difficulty reading.

TABLE IV-Seroconversion rates among HIV negative women in discordant couples

\begin{tabular}{|c|c|c|c|}
\hline & $\begin{array}{c}\text { No at } \\
\text { risk }\end{array}$ & $\begin{array}{c}\text { No } \\
\text { seroconverted }\end{array}$ & $\begin{array}{c}\text { Seroconversion } \\
\text { rate } / 100 \text { person } \\
\text { years } \\
(95 \% \text { confidence } \\
\text { interval })^{\star}\end{array}$ \\
\hline \multicolumn{4}{|l|}{$\begin{array}{l}\text { Literacy in native language } \\
\text { (Kinyarwanda): }\end{array}$} \\
\hline \multicolumn{4}{|l|}{ Woman illiterate or reads } \\
\hline Woman literate & 17 & 0 & $0(0$ to $7 \cdot 5)$ \\
\hline \multicolumn{4}{|l|}{ Marital status: } \\
\hline Common law union & 17 & 5 & $15 \cdot 0(4 \cdot 7$ to $31 \cdot 1)$ \\
\hline Legally married & 13 & 1 & $3.3(0.1$ to $13 \cdot 1)$ \\
\hline \multicolumn{4}{|l|}{ Type of partnership: } \\
\hline Man has other partners $\dagger$ & 22 & 6 & $13 \cdot 2(4 \cdot 8$ to $25 \cdot 9)$ \\
\hline Mutually monogamous & 8 & 0 & $0(0.1$ to $16 \cdot 8)$ \\
\hline \multicolumn{4}{|l|}{ Partner's alcohol intake: } \\
\hline Drinks a lot & 16 & 6 & $18 \cdot 6(6 \cdot 7$ to $36 \cdot 6)$ \\
\hline Drinks moderately & 14 & 0 & $0(0$ to $9 \cdot 6)$ \\
\hline Does not drink & 6 & 0 & $0(0$ to $23 \cdot 6)$ \\
\hline
\end{tabular}

${ }^{\star}$ Confidence intervals computed using the square root transformation for Poisson counts.

†None of the women reported other sexual partners during the period of the study.

All of the seroconverters were partners of heavy drinkers, and five reported having sex when the man had been drinking (the sixth did not answer the question). None of the 30 HIV negative women reported having sexual partners other than the HIV positive cohabiting partner identified during the period of the study. None of the female seroconverters had faithful male partners and only one was in a legal marriage; in comparison, half of non-converters had faithful partners and half were legally married. Seroconversion rates were not significantly different in couples reporting intercurrent venereal disease, sex during menses, lack of circumcision of the male, use of hormonal contraceptives, or symptoms associated with $\mathrm{HIV}$ in the infected partner.

ESTIMATES OF SEROCONVERSION RATES IN WOMEN IN UNIDENTIFIED DISCORDANT COUPLES

The seroconversion rate for HIV negative women who do not know that their steady partners are HIV positive was estimated as follows: during 1160 person years of follow up we observed 34 seroconversions among the cohort of 608 HIV negative women with cohabiting male partners who had not been tested for HIV. We assumed that the proportion of these 608 women who had HIV negative partners was the same as that among the 292 HIV negative women whose partners had been tested (89\%) because demographic data, sexual behaviour, and HIV prevalence among the women did not differ significantly between the couples tested and those not tested (table I). Then we assumed that the rate of seroconversion in these 541 ( $89 \%$ of 608 ) women was the same as that among the $260 \mathrm{HIV}$ negative women whose partners were known to be HIV negative $(0 \cdot 60 / 100$ person years) because seroconversion in that case would depend on the woman's outside sexual contacts and not on whether her steady partner had received HIV testing and counselling. It follows that six of the 34 observed seroconversions occurred in the $541 \mathrm{HIV}$ negative women whose partners were also HIV negative and the remaining 28 seroconversions occurred among the $67 \mathrm{HIV}$ negative women whose partners were HIV positive, a seroconversion rate of $22 / 100$ person years.

A sensitivity analysis was done by varying the two assumptions of the estimate to the limits of their $95 \%$ confidence intervals ( $85 \%$ to $92 \%$ for the proportion of HIV negative women with HIV negative partners, and $0 \cdot 11$ to $1 \cdot 45 / 100$ person years for the seroconversion rates of women in concordant HIV negative couples). Regardless of the values of the assumptions, the estimated seroconversion rate in unidentified discordant couples (between 12 and 35 per 100 person years) remained higher than the $9 / 100$ person years observed in couples who had received the intervention.

\section{Discussion}

In the absence of a vaccine or a cure for AIDS, changing risk behaviour is the only means available to reduce the sexual transmission of HIV infection. Consistent use of condoms reduces the risk of infection by blocking exchange of the virus and may reduce the efficacy of transmission by lowering the prevalence of a cofactor for HIV transmission, sexually transmitted diseases. ${ }^{19-21}$ This study documents a large increase in the reported use of condoms in $53 \mathrm{HIV}$ discordant couples. The combination of HIV testing and counselling was effective in motivating behaviour change and seems to have reduced the seroconversion rate.

Women whose cohabiting partners voluntarily came for HIV testing resembled the cohabiting women in the rest of the cohort in their seroprevalence and reported risk factors, differing only in their lower literacy rate. Thus, the sample is reasonably representative of childbearing couples in the city. ${ }^{15}$ This indicates that in Kigali, a city with a prevalence of HIV infection of over $30 \%$ among adults, ${ }^{14}$ roughly one in seven cohabiting couples is HIV discordant.

HIV testing had a strong positive effect on the safe sex behaviour of discordant couples. One year after the couples were enrolled in the study, use of condoms during vaginal intercourse was three times higher among discordant couples informed of their serostatus than among the 838 cohabiting couples in whom only the woman had been tested for HIV. High rates of condom use among couples who have been tested and found discordant have also been observed in other countries. ${ }^{2022-24}$ The finding that HIV testing and knowledge of discordance decreased the reported rate of unsafe sex in Rwanda suggests that HIV testing should be promoted in other African countries.

Condoms were used more consistently by discordant couples when the man was the HIV negative partner. Kamenga et al also found that use of condoms was more sustained in discordant couples when the man was HIV negative..$^{25}$ The effectiveness of any programme promoting condom use depends on its acceptance by the male partner. ${ }^{26}$ Some men interpret the request to use a condom as insulting, mistrustful, and a barrier to sexual fulfilment. ${ }^{27}$ An unsolved problem is how to encourage HIV positive men to use condoms consistently to protect their partners.

In all eight of the discordant couples in which the HIV negative partner seroconverted, the man was reported to drink alcohol regularly. The use of alcohol and other drugs has often been linked with sexual disinhibition and a failure to follow safe sex guidelines. ${ }^{28-31}$ Alcohol may have affected both the motivation and ability of discordant couples to use condoms effectively, resulting in increased risk of HIV infection.

All six of the seroconverting women were illiterate, compared with only $29 \%$ of the non-converters. Though the educational programme was presented orally, these women may have had greater difficulty understanding the intervention and learning the skills needed for effective use of condoms and spermicides. Special counselling may be needed for couples with limited language skills. 
There is evidence that some of the women in our study are underreporting their premarital sexual activity. Fifteen of the 25 positive women in discordant couples reported only one lifetime sexual partner and denied any blood transfusions during the period before the blood supply was screened for HIV. In cultures that value chastity in women this factor must be considered when interpreting self reported data.

The proportion of seropositive partners of seropositive women, $80 \%$ ( 103 of 128 ), while lower than the $90 \%$ found by Carael et al in Kigali in $1986^{5}$ is much higher than that observed in other partner studies. In the United Kingdom $5 \%$ of 18 male partners of seropositive women and $19 \%$ of 78 female partners of seropositive men were found to be seropositive. ${ }^{10}$ Similar figures from the United States range from $8 \%$ to $50 \% .{ }^{94}{ }^{242-34}$ In Africa only $15 \%$ of the partners of seropositive workers in Kinshasa, Zaire, were seropositive. ${ }^{13}$ We observed a much higher proportion of concordant seropositive couples in Rwanda $-80 \%$ of the partners of HIV positive women and $76 \%$ of the partners of HIV positive men were themselves seropositive. This may be due to a higher prevalence of cofactors (particularly sexually transmitted diseases) in the Rwandan population. Alternatively, the mean length of union was long in this sample -8 years - and may indicate a relatively longer duration of exposure to the HIV positive index case.

The rate of transmission of the virus per unprotected sexual contact with an infected individual was very low (1/286 in HIV negative men, 1/350 in HIV negative women), and the true rates could be even lower if our subjects underreported the number of unprotected episodes. This finding suggests that the risk of infection from one episode of penile-vaginal intercourse in Rwanda is similar to that in Western countries, on the order of $0.002 .{ }^{35}$

The seroconversion rate of $9 / 100$ person years $(6 / 100$ person years if women infected before the intervention are excluded) observed among HIV negative women in discordant couples is much lower than the $26 \%$ seroconversion rate observed in women in discordant couples during one year of follow up in Zambia. ${ }^{36} \mathrm{It}$ is also less than half the $22 / 100$ person years estimated for the seronegative women in unidentified, uncounselled discordant couples in our larger cohort.

Adults in cohabiting couples now comprise a large group at risk of HIV in the capital of Rwanda. Our study shows that many of these couples have discordant HIV serological results and will not be protected by staying mutually monogamous. Before learning of their test results, most discordant couples did not use condoms. HIV testing and counselling resulted in a noticeable increase in condom use and a lower rate of seroconversion in this group. Confidential HIV testing should be promoted in other African cities.

Grant support was provided by the Public Health Service (AI-23980, MH-42459) and the American Foundation for AIDS Research. Informed consent was obtained from the people participating in this study in accordance with the guideline of the United States Department of Health and Human Services and with the approval of the University of California, San Francisco, committee on human research and the government of Rwanda.

1 Holmes $\mathrm{K}$, Karon J, Kreiss J. The increasing frequency of heterosexually acquired AIDS in the United States, 1983-1988. Am f Public Healih 1990;80:858-62.

2 Mertens TE, Hayes RJ, Smith PG. Epidemiological methods to study the interaction between HIV infection and other sexually transmitted diseases. AIDS 1990; 4 :57-65.

3 Chin J, Mann J. Global surveillance and forecasting of AIDS. Bull WHO 1989;87:1-7.

4 Cameron DW, Simonsen JN, D'Costa LJ, Ronald AR, Maitha GM, Gakinya $M N$, et al. Female to male transmission of human immunodeficiency virus type 1: risk factors for seroconversion in men. Lancet 1989;i:403-7.
5 Carael M, Van de Perre PH, Lepage PH, Allen S, Nsengumuremyi F, Van Goethem $\mathrm{C}$, et al. Human immunodeficiency virus transmission among heterosexual couples in Central Africa. AIDS 1988;2:201-5.

6 European Study Group. Risk factors for male to female transmission of HIV. BMF 1989;298:411-5.

7 Johnson AM, Laga M. Heterosexual transmission of HIV. AIDS 1988;2: S49-56.

8 Laga M, Taelman H, Van der Stuyft P, Bonneux L, Vercauteren G, Piot P. Advanced immunodeficiency as a risk factor for heterosexual transmission of HIV. AIDS 1989;3:361-6.

9 Peterman TA, Stoneburner RL, Allen JR, Jaffe HW, Curran JW. Risk of human immunodeficiency virus transmission from heterosexual adults with transfusion-associated infections [published erratum appears in JAMA 1989 Jul 28;262(4):502]. FAMA 1988;259:55-8.

10 Johnson AM, Petherick A, Davidson SJ, Brettle R, Hooker M, Howard L, et al. Transmission of HIV to heterosexual partners of infected men and women. AIDS 1989;3:367-72.

11 Padian NS, Shiboski SC, Jewell NP. The effect of number of exposures on the risk of heterosexual HIV transmission. F Infect Dis 1990;161:883-7.

12 Kreiss J, Kitenen L, Prince H. Antibody to human T-lymphotropic virus type III in wives of hemophiliacs: evidence for heterosexual transmission. Ann Intern Med 1985;102:632-6.

13 Ryder RW, Ndilu M, Hassig SE, Kamenga M, Sequira D, Kashamuka M, et al. Heterosexual transmission of HIV-1 among employees and their spouses at two large businesses in Zaire. AIDS 1990;4:725-32.

14 Allen S, Van de Perre P, Serufilira A, Lepage F, Carael M, DeClercq A, et al. Human immunodeficiency virus and malaria in a representative sample of childbearing women in Kigali, Rwanda. F Infect Dis 1991;164:67-71.

15 Allen S, Lindan C, Serufilira A, Van de Perre F, Rundle AC, Nsengumuremy $\mathrm{F}$, et al. Human immunodeficiency virus infection in urban Rwanda. FAMA 1991;266:1657-63.

16 Snedecor GW, Cochran WG. Statistical methods. 7th ed. Ames, Iowa: Iowa State University Press, 1980.

7 Johnson NL, Kotz S. Discrete distributions. Boston: Houghton-Mifflin, 1969.

18 King R, Van de Perre P, Allen S, Serufilira A, Homsy J. Predictive value of indeterminate HIV western blot. Lancet 1991;338:1278.

19 Feldblum PJ, Fortney JA. Condoms, spermicides, and the transmission of human immunodeficiency virus: a review of the literature. Am $\mathcal{f}$ Public human immunodeficien

20 Kamenga M, Jingu K, Hassig S, Mdilu N, Behets F, Brown C, et al. Condom use and associated HIV seroconversion following intensive HIV counselling of 122 married couples in Zaire with discordant HIV serology. Fifth of 122 married couples in Zaire with discordant HIV serology. Fifth international conference on AIDS, Montreal, 1989. O
Development Research Center, 1989: abstract TDO 35.

21 Mann J, Quinn T, Piot P, Bosenge N, Nzilambe N, Kalala M, et al. Condom use and HIV infection among prostitutes in Zaire. $N$ Engl $\mathcal{I}$ Med 1987;316:345.

22 Laurian Y, Peynet J, Verroust F. HIV infection in sexual partners of HIV seropositive patients with hemophilia [letter] [published erratum appears in N Engl f Med 1989 Jul 27;321:268). N Engl f Med 1989;320:183.

23 Perroni L, Le Foche L, De Stefano G, De Longis P, Albertoni F, Soscia F. Transmission of HIV infection in heterosexual partners of HIV +drug addicts. Fifth international conference on AIDS, Montreal, 1989. Ottawa: International Development Research Center, 1989: abstract TAP 113.

24 Fischl MA, Dickinson GM, Scott GB, Klimas N, Fletcher MA, Parks W Evaluation of heterosexual partners, children, and household contacts of Evaluation of heterosexual partners, child
adults with AIDS. fAMA 1987;257:640-4.

25 Kamenga M, Ryder RW, Jingu M, Mbuyi N, Mbu L, Behets F, et al. Evidence of marked sexual behavior change associated with low HIV-I Evidence of marked sexual behavior change associated with low HIV-1
seroconversion in 149 married couples with discordant HIV-1 serostatus: seroconversion in 149 married couples with discordant HIV-1 seros
experience at an HIV counselling center in Zaire. AIDS 1991;5:61-7.

26 Stein ZA. HIV prevention: the need for methods women can use. Am $\mathcal{F}$ Public Health 1990;80:460-2.

27 Larson A. Social context of human immunodeficiency virus transmission in Africa: historical and cultural bases of east and central African sexual relations. Rev Infect Dis 1989;11:716-31.

28 Robertson JA, Plant MA. Alcohol, sex and risks of HIV infection. Drug Alcohol Depend 1988;22:75-8.

29 Sheehan A. HIV. Negative images. Nursing (Lond) 1990;4:13-4

30 Silvestre AJ, Lyter DW, Valdiserri RO, Huggins J, Rinaldo CJ. Factors related to seroconversion among homo- and bisexual men after attending risk-reduction educational session. AIDS 1989;3:647-50.

31 Stall R, McKusick L, Wiley J, Coates TJ, Ostrow DG. Alcohol and drug use during sexual activity and compliance with safe sex guidelines for AIDS: the during sexual activity and compliance with safe sex guidelines for AIDS

32 Lawrence DN, Jason JM, Holman RC, Heine P, Evatt BL. Sex practice correlates to human immunodeficiency virus transmission and acquired immunodeficiency syndrome incidence in heterosexual partners and offspring of US hemophilic men. Am $\mathcal{F}$ Hematol 1989;30:68-76.

33 Smiley ML, White GC, Becherer P, Macik G, Matthews TJ, Weinhold KJ, et al. Transmission of human immunodeficiency virus to sexual partners of hemophiliacs. Am f Hematol 1988;28:27-32.

34 Padian N, Marquis L, Francis DP, Anderson RE, Rutherford GW, O'Malley $\mathrm{PM}$, et al. Male-to-female transmission of human immunodeficiency virus. JAMA 1987;258:788-90.

35 Hearst N, Hulley SB. Preventing the heterosexual spread of AIDS. Are we giving our patients the best advice? FAMA 1988;259:2428-32.

36 Hira SK, Nkowane BM, Kamanga J, Wadhawan D, Kavindele D, Macuacua $\mathrm{R}$, et al. Epidemiology of human immunodeficiency virus in families in Lusaka, Zambia. F Acquir Immune Defic Syndr 1990;3:83-6.

(Accepted 2 April 1992)

\section{Correction}

\section{Management of elderly patients with sustained}

\section{hypertension}

An authors' error occurred in this paper by Keith Beard and colleagues (15 February, $p$ 412-6). In the table the age range for the SHEP trial should have been $60-\geqslant 80$. 